\title{
Um Enfoque Keynesiano sobre a Credibilidade da Política Monetária
}

\author{
A Keynesian Approach to the Credibility of Monetary Policy
}

GILBERTO DE ASSIS LIBÂNIO****

RESUMO: A perspectiva tradicional de credibilidade segue a nova posição clássica no debate "regras vs. discrição", ou seja, argumenta-se que a credibilidade é obtida se, e somente se, a autoridade monetária for mantida afastada de políticas discricionárias ("mãos atadas"). Isso, no entanto, depende da hipótese da nova doutrina clássica e pode não ser válido em modelos que abrem a possibilidade de múltiplos equilíbrios. Este artigo tenta discutir a questão da credibilidade à luz do modelo pós-Keynesiano, oferecendo uma alternativa à visão dominante sobre esse tema.

PALAVRAS-CHAVE: Política monetária; pós-keynesianismo; credibilidade.

ABSTRAC: The traditional perspective on credibility follows the new classical position on the "rules vs. discretion" debate. i.e., it is argued that credibility is obtained if, and only if, the monetary authority is kept away from discretionary policies ("tied hands"). This, however, depends on the hypothesis of the new classical doctrine and may not be valid in models that open the possibility of multiple equilibria. This paper tries to discuss the question of credibility under the lights of the post-Keynesian model, offering an alternative to the mainstream view about this theme.

KEYWORDS: Monetary policy; post-Keynesianism; credibility.

JEL Classification: E52; E58.

\section{INTRODUÇÃO}

A temática da credibilidade se encontra presente de forma clara e inequívoca na discussão cotidiana sobre política econômica. De fato, ela tem sido frequentemente apontada como uma variável que influencia as relações entre governo e agentes privados e, por extensão, afeta os próprios resultados da política econômica.

\footnotetext{
* Professor do Departamento de Economia da Faculdade de Ciências Econômicas da Universidade Federal de Minas Gerais - FACE/UFMG, e-mail: gilberto@cedeplar.ufmg.

* O autor agradece ao professor Fernando Cardim de Carvalho, cujos comentários muito enriqueceram este trabalho. Os equívocos e omissões do texto são de inteira responsabilidade do autor.
} 
A visão hegemônica sobre credibilidade — que pode ser considerada uma extensão da teoria novo-clássica e se relaciona à "inconsistência dinâmica de planos ótimos" (Kydland e Prescott, 1977) - tem como fundamento a suposição de que o sistema econômico é eminentemente estável e que políticas ativas são, além de desnecessárias, nocivas . Ademais, sugere que a política monetária só seria eficaz se inesperada e que, portanto, policy makers teriam estímulo a "trapacear", para promover elevações (ainda que transitórias) no nível de produto. A credibilidade, nesse caso, se relaciona à expectativa de que a política monetária não seja alterada, e poderia ser obtida através de mecanismos que impossibilitassem atuação discricionária por parte das autoridades monetárias ("mãos atadas" ). ${ }^{1}$

Vale frisar, todavia, que a sustentação das conclusões extraídas dos modelos de credibilidade e reputação, bem como de suas prescrições normativas, vincula-se à aceitação dos pressupostos que fundamentam a teoria novo-clássica. Nesse sentido, desempenha papel crucial a suposição de que economias modernas podem ser adequadamente descritas por um modelo de equilíbrio geral. Dito de outra forma, é fundamental a suposta existência de uma "taxa natural de desemprego" — única e estável - que funciona como ponto de atração do sistema econômico.

Assim, o abandono de qualquer dos pressupostos daquela teoria invalida as proposições sobre credibilidade resumidas acima. Isto é, a consideração de um sistema econômico que admite equilíbrios múltiplos leva a outros resultados quanto à operação da política monetária e, logo, à necessidade de se adotar uma perspectiva distinta para o problema da credibilidade.

A próxima seção procura descrever, em linhas gerais, uma abordagem alternativa baseada em Keynes, levando em consideração suas advertências quanto à inadequação da teoria (neo)clássica para economias capitalistas e, logo, quanto à inaplicabilidade direta de suas conclusões (Keynes, 1982, cap. 1). Em seguida, busca-se explorar o papel e as formas de atuação da política monetária no modelo póskeynesiano. Por fim, pretende-se discutir como a questão da credibilidade pode ser colocada nesse novo contexto, fornecendo um contraponto à visão hoje dominante sobre o tema.

\section{DETERMINAÇÃO DO PRODUTO E EMPREGO EM KEYNES}

A obra de Keynes representa uma tentativa de construir um paradigma alternativo à economia (neo)clássica, rejeitando a visão de que o sistema econômico é eminentemente estável e auto-regulável. Para tanto, um elemento central é a consideração do papel da moeda em economias capitalistas modernas.

Na teoria clássica, a moeda é somente uma conveniência, um "véu que encobre as trocas", evitando problemas como indivisibilidade de bens e dupla coincidência de desejos. Nesse sentido, o dinheiro se restringe a um meio de troca, não exercen-

\footnotetext{
${ }^{1}$ Ver, por exemplo, Blackburn e Christensen (1989) e Persson e Tabellini, orgs. (1994).
} 
do influência alguma sobre o processo de produção e acumulação. Em última instância, é como se a troca se desse diretamente entre produtos (a moeda é neutra). Consequentemente, fica validada a "Lei de Say", segundo a qual toda oferta cria sua própria demanda (em termos agregados), sendo eventuais desequilíbrios setoriais automaticamente corrigidos pela variação dos preços relativos. ${ }^{2}$

Keynes ressalta a inadequação da teoria ortodoxa para economias reais e busca construir — alternativamente - uma "teoria monetária da produção":

"The theory which I desiderate would deal (...) with an economy in which money plays a part of its own and affects motives and decisions and is, in short, one of the operative factors in the situation, so that the course of events cannot be predicted, either in the long period or in the short, without a knowledge of the behaviour of money between the first state and the last. And it is this which we ought to mean when we speak of a monetary economy" (CWJMK, XIII, pp. 408-9).

Assim, trata-se da concepção de um sistema que enfatiza a não-neutralidade da moeda, mesmo a longo prazo. Para tanto, requer-se o abandono de alguns axiomas da teoria neoclássica e o desenvolvimento de princípios alternativos, a partir dos quais se explicite o funcionamento de uma economia monetária de produção. Segundo Davidson (1984), três seriam os axiomas da teoria neoclássica descartados por Keynes. Primeiro, o axioma da substitutibilidade bruta, que afirma que todos os bens e serviços são, em alguma medida, substitutos entre si. Em seguida, o axioma dos reais, segundo o qual os objetivos de agentes "racionais" não incluem variáveis nominais. Por fim, abandona-se o axioma da ergodicidade, que assume a estacionaridade nos processos econômicos e, logo, nas condições sob as quais os agentes tomam decisões.

O modelo proposto por Keynes consideraria, em substituição a tais axiomas, elementos como a não-neutralidade da moeda, a não-ergodicidade do sistema econômico e a existência de contratos futuros denominados em moeda. A partir desses elementos, é possível construir uma alternativa à "Lei de Say", enquanto mecanismo fundamental de determinação da renda, abrindo espaço para a ocorrência de insuficiências de demanda efetiva, que explicariam a existência de desemprego involuntário.

O nível de emprego (e, dada a técnica, de renda) na teoria de Keynes é determinado pelo ponto de demanda efetiva, definido pela interseção das funções de oferta e demanda agregadas ${ }^{3}$. A primeira, que pode ser escrita como $Z=q>(N)$, mostra o volume agregado de emprego que as firmas ofereceriam para cada nível

\footnotetext{
${ }^{2}$ A rigor, em modelos de equilíbrio geral, a correção de preços relativos é feita ex-ante, não se admitindo a possibilidade de "falsas trocas".

${ }^{3}$ A construção de tais curvas toma como dados: a) a tecnologia; b) o grau de competição (ou monopólio); c) a distribuição funcional da renda; d) as preferências dos consumidores; e) o rendimento dos fatores de produção.
} 
de receitas esperadas - decorrentes da venda de sua produção. Graficamente, a curva de oferta agregada $(Z)$ apresenta inclinação positiva, representando a noção intuitiva de que uma maior expectativa de vendas induz a uma maior contratação de mão de obra.

A função de demanda agregada, por sua vez, indica o volume total de gastos para diferentes níveis de emprego: $\mathrm{D}=\mathrm{f}(\mathrm{N})$. Sua inclinação é também positiva, pois "if employment is larger, more income is earned, and therefore the demand (spending) on goods and services will be larger." (Davidson, 1994, pp. 19-20).

O ponto de demanda efetiva representa o equilíbrio do sistema, na medida em que, nesse ponto, as expectativas dos empresários são confirmadas, não havendo, portanto, estímulo a alterar o volume de emprego oferecido. Em outras palavras, o ponto de demanda efetiva determina um nível de emprego no qual as receitas esperadas igualam os gastos realizados, não se observando desapontamento de expectativas.

Cabe destacar que tal modelo de determinação do emprego apresenta algumas diferenças fundamentais em relação à hipótese da taxa natural de desemprego. A primeira delas diz respeito à volatilidade dos determinantes do equilíbrio. Nesse sentido, exerce papel importante a formulação de expectativas em um ambiente de incerteza, especialmente por sua influência na determinação dos gastos em investimento. Por um lado, por afetar a preferência pela liquidez, que é um dos elementos que influencia a taxa de juros no modelo de Keynes. Por outro, através da eficiência marginal do capital, que depende de expectativas quanto ao rendimento futuro dos bens de capital e determina - junamente co $\mathrm{m}$ a taxa de juros - o volume de investimento.

Assim, por depender de expectativas - que podem ser voláteis - o investimento agregado está sujeito a fortes oscilações, o que desloca a curva de demanda agregada e, portanto, altera o ponto de demanda efetiva, determinando valores variáveis para o nível de emprego (de equilíbrio). Segundo Keynes (1982, p. 121 ):

"É importante compreender a dependência que há entre a eficiência marginal de determinado volume de capital e as variações na expectativa, pois é principalmente essa dependência que torna a eficiência marginal do capital sujeita a certas flutuações violentas que explicam o ciclo econômico".

Outra distinção importante frente à taxa natural de desemprego - e ainda relacionada à anterior - se refere à multiplicidade de equilíbrios. Ao invés de supor que o sistema se equilibre com um único nível de emprego, o modelo de Keynes admite equilíbrios múltiplo s. Nesse caso, o resultado depende do estado de expectativas de longo termo - que condiciona as decisões de investimento — e da política monetária, que afeta as taxas de juros. Ca be ressaltar o contraste em relação à visão convencional, que afirma a ineficácia de tal política frente a variações no 
produto e emprego. ${ }^{4} \mathrm{Na}$ teoria pós-keynesiana, a moeda não é neutra, mesmo a longo prazo, por afetar - através da taxa de juros — a demanda por bens de capital, influenciando a trajetória do sistema no longo período.

Note-se que a admissão de múltiplos equilíbrios elimina a suposição de que o pleno emprego seria o único resultado possível. Este passa a ser visto como uma situação limite entre as várias posições de equilíbrio, e que só ocorreria se os gastos em investimento fossem exatamente suficientes para suprir a lacuna entre a renda "potencial" e o consumo nesse nível de renda. "A demanda efetiva associada ao pleno emprego é um caso especial que só se verifica quando a propensão a consumir e o incentivo para investir se encontram associados entre si numa determinada forma." (Keynes, 1982, p. 40).

Por fim, uma última questão a ser destacada diz respeito à falta de mecanismos de convergência automática ao pleno emprego. Diferentemente da teoria clássica, o modelo de Keynes não supõe um contínuo clearing do mercado de trabalho, ou a hipótese de que as "forças de mercado" levariam o sistema a um ponto de equilíbrio determinado pela interseção das curvas de demanda e oferta de trabalho. Ao abandonar o que chama de "segundo postulado da teoria clássica" - que afirma que a utilidade do salário é igual à desutilidade marginal do trabalho -, Keynes justifica a proposição de que o nível de emprego se estabelece somente pela curva de demanda por trabalho, sendo a curva de oferta uma fronteira dos possíveis pontos de equilíbrio (situados à sua esquerda).

\section{O PAPEL DA POLÍTICA ECONÔMICA NA TEORIA PÓS-KEYNESIANA}

A existência de equilíbrio com desemprego, decorrente de insuficiência de demanda agregada, possibilita a concepção de papéis ativos para o Estado na promoção do pleno emprego. Referindo-se à depressão por que passava a economia inglesa no início dos anos 30, Keynes afirma: "The system is not self-adjusting and, without purposive direction, it is incapable of translating our actual poverty into our potential plenty." (CWJMK, XIII, p. 491).

Minsky (1986) também destaca o caráter intrinsecamente instável do sistema capitalista, mostrando como tal instabilidade se relaciona às formas de financiamento do investimento. Isto é, a natureza especulativa de tal financiamento, segundo a qual dívidas são criadas no processo de aquisição de ativos produtivos, pode fazer com que movimentos recessivos sejam ampliados (ao invés de auto-corrigidos) através de sucessivas bancarrotas de devedores interligados com dificuldades de saldar seus débitos. Minsky discute ainda como — em tais circunstâncias - a

\footnotetext{
${ }^{4}$ Nesse caso, toma -se a visão novo clássica como referência, em particular por sua influência sobre grande parte dos trabalhos que discutem a credibilidade da política monetária (conforme mencionado anteriormente). Obviamente, isso não significa dizer que a unicidade do equilíbrio seja consensual no interior da ortodoxia, já que a ideia de equilíbrios múltiplos é também explorada e amplamente aceita. Pode -se mencionar, por exemplo, algumas contribuições de F. Hahn (1981, 1984).
} 
política econômica (fiscal e monetária) teria um papel relevante a desempenhar para evitar a ocorrência de uma profunda recessão (como se verá em seguida).

Todavia, a postura ativista de Keynes (e seus seguidores) não pode ser inteiramente justificada apenas pela detecção de problemas sistêmicos na economia. A proposição de que o "livre mercado" gera resultados insatisfatórios não implica necessariamente que a intervenção estatal seja desejável. ${ }^{5} \mathrm{O}$ ativismo de Keynes decorre também de sua visão de que é possível formar uma burocracia pública eficiente e bem preparada para a gestão da política econômica, assim como de sua convicção de que o intervencionismo não representa — em si mesmo — uma ameaça à liberdade individual.

Ademais, reconhece-se que o Estado dispõe de instrumentos importantes para influenciar a economia. Ou seja, por sua grande capacidade de mobilizar recursos, de moldar instituições, de criar moeda, de correr riscos e, principalmente, por possuir capacidade institucional de alterar os horizontes de expectativas dos agentes privados e de afetar o grau de incerteza no ambiente em que tais expectativas são formadas, o Estado se diferencia de qualquer agente privado e pode, em grande medida, direcionar a trajetória do sistema: "Policy can change both the details and the overall character of the economy." (Minsky, 1986, p. 7).

Admitidas a possibilidade e a conveniência da intervenção governamental, cabe discutir os instrumentos e canais de atuação da política econômica. ${ }^{6}$ Keynes sustenta que a formulação e gestão da política macroeconômica deve ser abrangente, englobando simultaneamente ações em diversas frentes, todas elas coordenadas entre si. Tão importante quanto a definição de instrumentos específicos de política monetária e/ou fiscal seria a necessidade de coordenação entre tais políticas.

Assim, ao contrário da postura fiscalista que caracteriza o keynesianismo dominante no pós-Guerra, a visão de Keynes é de que as políticas fiscal e monetária sejam tomadas como complementares - e não substitutas -, atuando de forma simultânea e coordenada, e ajustando-se a cada situação específica.

Primeiramente, destaca-se a influência direta da política econômica sobre variáveis relevantes na determinação da renda e do emprego. Nesse sentido, a política fiscal representa um instrumento importante, ao elevar o gasto agregado e detonar um efeito multiplicador da renda. Segundo Minsky (1986), o governo deve ter um padrão de gastos suficientemente alto para contrabalançar eventuais quedas dos investimentos privados ("Big Government"), estabilizando a demanda agregada e os lucros. Não se trata, entretanto, de defender a crônica geração de déficits públicos, tal como a postura adotada algumas vezes pela Síntese Neoclássica e frequentemente atribuída (de forma equivocada) ao próprio Keynes. Propõe-se um

\footnotetext{
5 'É comum entre teóricos liberais (como Hayek) a defesa de que as "falhas de mercado" sejam preferiveis às "falhas de Estado".

${ }^{6} \mathrm{O}$ enfoque será concentrado sobre as políticas de manejo da demanda agregada (em particular, a política monetária), não sendo aqui tratadas outras esferas de atuação pública, como as políticas industrial, comercial e de rendas.
} 
regime de tributação e gastos tal que o orçamento público seja deficitário com a economia em retração e superavitário em períodos de expansão, funcionando assim como um estabilizador automático de demanda. O resultado final deveria ser positivo "under reasonable and attainable circumstances" (Minsky, 1986, p. 302), evitando o crescimento explosivo da dívida pública e a necessidade de condições cada vez menos favoráveis ao governo para a obtenção de empréstimos.

A política monetária, por sua vez, busca influenciar a taxa de juros através da variação da oferta de moeda, com impacto sobre os níveis de investimento. De acordo com Carvalho (1994, p. 47):

"Concebe-se a política monetária como a manipulação do estoque de moeda com o fim de modificar a taxa de juros sobre os ativos líquidos, para, através de efeitos sobre o portfolio dos agentes privados, induzir movimentos de substituição das formas de riqueza, aumentando ou diminuindo a demanda por ativos reprodutíveis e, assim, aumentando ou diminuindo a renda gerada na produção de novos itens".

Para Keynes, o principal canal de transmissão da política monetária seriam as operações de mercado aberto. Sua influência sobre a taxa de juros poderia se dar tanto pela alteração do volume de moeda como pela mudança de expectativas em relação à política futura.

Keynes defende que a política monetária deve ter papel acomodativo. Isto é, a oferta de moeda deveria acompanhar oscilações em sua demanda — causadas por variações do produto nominal e no grau de preferência pela liquidez-, buscando manter certa estabilidade nos termos de crédito e evitar impactos negativos sobre a atratividade dos bens de investimento.

Por outro lado, a política monetária pode ter efeitos positivos sobre a renda e o emprego ao afetar o valor dos ativos e a solvência de firmas e instituições financeiras. Isso se relaciona ao papel de emprestador em última instância assumido pela autoridade monetária, que se dispõe a comprar papéis com alto risco e baixa liquidez, substituindo-os por títulos do próprio BC (mais seguros e mais líquidos), melhorando assim o perfil do portfolio das empresas. De acordo com Minsky (1986, p. 40), "refinancing a position or (... ) enabling a bank or a financial market to withstand a run, is the essential lender-of-last-resort function".

Em segundo lugar, mas não menos importante, deve-se considerar o impacto indireto da política econômica, por seu papel de sinalização aos agentes privados e redução de incertezas. Nesse caso, a influência sobre o produto se daria através do impacto sobre as "variáveis psicológicas fundamentais" do modelo de Keynes, particularmente, a preferência pela liquidez e a eficiência marginal do capital.

Para Keynes, a preferência pela liquidez é a responsável direta — dada a oferta monetária - pela determinação da taxa de juros. Esta seria a taxa que iguala a demanda e oferta de recursos para entesouramento. A primeira relaciona-se às demandas precaucionária e especulativa por moeda, enquanto a última corresponde ao estoque total de moeda, descontado o montante da mesma requerido para 
transações correntes. A taxa de juros serviria então como um estímulo para não entesourar moeda. Ou ainda, segundo as palavras do próprio Keynes, "the rate of interest obviously measures (... ) the premium which has to be offered to induce people to hold their wealth in some form other than hoarded money." (CWJMK, XIV, p. 116). A política monetária pode, ao promover cenários mais seguros do futuro, afetar a preferência pela liquidez, reduzindo o prêmio exigido pelos agentes para abrir mão da moeda, i. e., a taxa de juros. Uma queda desta última levaria, ceteris paribus, a uma maior atratividade dos ativos reprodutíveis e, logo, a uma elevação nos níveis de investimento agregado (e renda).

Cabe notar que, nesse caso, uma operação de mercado aberto - uma vez anunciada - pode inclusive tornar-se desnecessária. Isto é, a mera declaração de uma ação de política monetária pode ser suficiente para alterar as expectativas dos agentes privados e, em consequência, a taxa de juros considerada "normal". Quanto mais forte esse "efeito declaração", menor atuação efetiva se faz necessária por parte da autoridade monetária.

A segunda "variável psicológica" influenciada pela política económica é a chamada eficiência marginal do capital, estreitamente relacionada à expectativa de rendimento futuro dos bens de investimento. Conforme foi dito, decisões de investir são tomadas sobre bases precárias de conhecimento sobre o futuro, envolvendo conjecturas. De acordo com Keynes:

"As considerações sobre as quais se baseiam as expectativas de rendas esperadas são, em parte, fatos existentes que se pode supor sejam conhecidos mais ou menos com certeza e, em parte, eventos futuros que podem ser previstos com um maior ou menor grau de confiança." (Keynes, 1982, p. 123).

A concepção de políticas monetárias (e fiscais) de longo prazo poderia induzir a formação de expectativas sobre uma certa estabilidade na demanda agregada e nas condições de crédito, aumentando o grau de confiança de eventuais investidores em suas previsões sobre o futuro e reduzindo seus riscos ${ }^{7}$, com impactos positivos sobre o investimento privado. Em outras palavras, um déficit público tenderia a estabilizar renda e lucros em períodos recessivos, enquanto a autoridade monetária garantiria o valor dos ativos e reduziria o risco de inadimplência.

Observa-se, em última instância, que a elaboração e os impactos da política monetária relacionam-se estreitamente com a reação dos agentes privados ou, mais particularmente, com a influência sobre as variáveis comportamentais antes discutidas. Isso significa que é necessário atentar para a interação entre os setores público e privado, a partir da qual se estabelecem os resultados da política econômica. Nas palavras de Carvalho (1994), "o efeito de qualquer política econômica que

\footnotetext{
${ }^{7}$ Trata-se aqui de reduzir o risco global, macroeconômico. O risco individual faz parte das regras do jogo capitalista. Como afirma Carvalho (1997, p. 41): "Governments cannot create stable microeconomic contexts. Agents must still run the risks associated with their accumulation choices”.
} 
não seja a compulsão direta depende da avaliação dos agentes a respeito de seus objetivos, da sua sustentabilidade e de outros fatores da mesma natureza". Descartamse, dessa forma, visões mais mecanicistas a respeito da operação da política econômica, como a da Síntese Neoclássica no pós-guerra.

Em se tratando da política monetária, seus resultados dependem da preferência pela liquidez do público e do setor bancário. Particularmente, o comportamento deste último é fundamental, por representar o canal básico de operação daquela política. ${ }^{8}$ A reação dos bancos e intermediários financeiros pode levar a resultados distintos daqueles buscados pelo BC. A moeda, nesse caso, teria certo grau de endogeneidade, de acordo com a demanda e a capacidade do setor bancário de criar "quase-moedas" (inovação financeira): "Banking forces the hands of the monetary authorities." (Minsky, 1986, p. 243). Por exemplo, uma tentativa de elevar a oferta monetária pode ser quase completamente anulada se os bancos elevam suficientemente seu volume de reservas, inibindo a operação do multiplicador monetário.

\section{CREDIBILIDADE E POLÍTICA MONETÁRIA: UMA VISÃO ALTERNATIVA}

A consideração de variáveis comportamentais e da relação entre policy makers e agentes privados leva diretamente a questões ligadas à credibilidade da política econômica. Nesse sentido, o descrédito em relação a determinada política poderia impedir a influência desejada sobre o comportamento do público - ou ainda, detonar reações contrárias - dificultando (ou mesmo impossibilitando) a consecução dos objetivos traçados. Ou seja, o resultado final não é independente da reação dos agentes privados e tende a ser mais satisfatório quanto maior a credibilidade da política implementada. Referindo-se à operação da política monetária, Keynes afirma: "The question of how much aditional liquidity is required cannot be settled beforehand and must depend on the touch of the market. It will largely depend on the confidence felt in Treasury intentions." (CWJMK, XXI, p. 562).

Todavia, $\mathrm{o}$ argumento não pode se limitar a atribuir bons resultados à presença de credibilidade e maus resultados à sua ausência. É necessário discutir que elementos estariam ligados à construção da credibilidade e quais seriam as proposições normativas daí decorrentes.

A visão ortodoxa sobre o tema é a de que uma política obtém credibilidade se há expectativa de que ela não seja alterada. Daí a defesa de regras fixas e de gestores com baixo grau de arbítrio. Todavia, tal postura decorre da proposição de que a política econômica só é eficaz se inesperada e que, portanto, policy makers sempre teriam estímulo a trapacear, para mover a economia de suas "taxas naturais".

Entretanto, sob a ótica pós-keynesiana, que considera a noção de incerteza e

\footnotetext{
${ }^{8}$ A menos que se admita — como Friedman — a hipótese do helicóptero que descarrega dinheiro sobre a economia.
} 
admite a possibilidade de múltiplos equilíbrios, outras são as "formas de operação" da política monetária e, como é óbvio, outro o enfoque a ser buscado para discutir a questão da credibilidade. Nesse sentido, colocam-se duas questões fundamentais, que tornam mais claras as divergências propositivas entre as visões novo-clássica e pós-keynesiana.

Em primeiro lugar, descarta-se a noção de que a eficácia da política monetária depende de sua imprevisibilidade. Pois, se a promoção de cenários mais seguros do futuro - reduzindo a incerteza dos investidores - é um dos principais papéis da política econômica, é conveniente que ela seja anunciada a priori. Ademais, o comportamento do público pode ser melhor influenciado em favor dos objetivos da política quando estes são claramente debatidos e entendidos, o que contribui para um desempenho mais satisfatório. Um exemplo bastante claro é o chamado "efeito declaração" - mencionado anteriormente - em que a simples divulgação das ações de política monetária reduz a necessidade de atuação efetiva.

Portanto, ao contrário da visão novo-clássica, segundo a qual a eficiência de uma política depende da "surpresa " que ela provoca, defende-se aqui o anúncio prévio dos objetivos do governo e das políticas delineadas para atingi-los, sem que isso implique a ineficácia de tal política. Assim, o governo indicaria aos agentes quais seriam os valores buscados para as variáveis sob influência da política econômica. Referindo-se à política monetária, Keynes afirma:

"I attach enormous importance particularly in the long period to getting rid of unnecessary secrecy and mystery of all kinds. (... ) I think also that greater publicity of all kinds will lead to better understanding by the market of what the Bank's intentions are, and will facilitate those intentions being carried into effect quicker and with more certainty. It nearly always pays the market to adapt itself to the real intentions of the Bank." (CWJMK, XX, pp. 262-3).

Em segundo lugar, deve-se questionar qual o grau de arbítrio reservado aos policy makers. Argumenta-se aqui, em direção oposta à defesa de "mãos atadas", que a incerteza quanto ao futuro e a necessidade de adequar a política econômica a situações específicas exigem dos gestores certa capacidade de mudança e adaptação. Não é provável atribuir credibilidade a uma política que, desenhada para certa conjuntura, seja mantida quando tal conjuntura não mais prevaleça. Considerase, nesse caso, a possibilidade de que o sistema econômico evolua e se altere, de modo que políticas adequadas e efetivas em determinadas circunstâncias deixem de sê-lo em outras. "A abordagem keynesiana defende, assim, não apenas a intervenção pública na economia, mas também o grau de discreção que for necessário para o enfrentamento das novas, em sentido essencial, situações que o futuro pode trazer." (Carvalho 1994, p. 54).

Por outro lado, cabe destacar que o papel de emprestador em última instância exercido pelo banco central requer também certa flexibilidade na operação da política monetária. Nas palavras de Minsky (1986, p. 55): 
"It is important to emphasize that, because the Federal Reserve System is directly or indirectly the lender of last resort to the financial system as it exists, any constraint placed on Federal Reserve flexibility (e.g., by mandating mechanical rules of behavior) attenuates its power to act. Rules cannot substitute for lender-of-last-resort discretion".

Não se trata, entretanto, de defender uma completa ausência de regras e padrões de atuação. Conforme mencionado anteriormente, a política econômica tem importante papel de sinalização sobre o futuro e, portanto, seriam desejáveis certas normas para sua gestão, buscando evitar uma atuação muito errática por parte dos policy makers, o que dificultaria aos agentes privados a percepção dos objetivos da política e a construção de cenários mais claros quanto às condições macroeconômicas futuras.

Ademais, uma atuação muito errática é dificultada pelas próprias regras de funcionamento do sistema econômico. No caso da política monetária, em particular, um limite é estabelecido pela necessidade de preservação do padrão monetário, que requer - conforme foi dito - que a moeda tenha baixa elasticidade de produção. Pois, é certo que uma pré-condição para a operação da política monetária é a preservação do próprio padrão monetário.

Assim sendo, a questão da credibilidade passa a ser vista sob uma perspectiva distinta. Se o sistema é intrinsecamente instável e requer eventuais intervenções da autoridade monetária, por que atribuir mais credibilidade a uma instituição sem qualquer raio de manobra e que, portanto, não pode atuar quando se faz necessário? Nesse caso, a credibilidade se relacionaria não à percepção de que a política monetária não possa ser alterada, mas sim de que ela seja apropriada a uma conjuntura específica e ao fato de o banco central poder operar adequadamente as intervenções que se fizerem necessárias.

De modo geral, a credibilidade de determinada política parece estar associada a sua consistência. Para ser considerada consistente, a política monetária deve atender a alguns requisitos. ${ }^{9}$

Primeiramente, deve ser percebida como "correta" e adequada à conjuntura para a qual foi elaborada. É óbvio que tal percepção não é independente da teoria econômica adotada pelos diversos agentes privados e pelos formuladores da política. Parece provável, por exemplo, que uma regra fixa de emissão (à la Friedman) possa ser considerada inadequada em um contexto de crise financeira, se uma parcela significativa do público considera necessária uma intervenção do banco central como emprestador em última instância (à la Minsky). ${ }^{10}$

\footnotetext{
${ }^{9}$ Esta listagem não se pretende exaustiva. Apenas busca indicar alguns elementos - mais ou menos objetivos - que possam influenciar a credibilidade da política monetária (um conceito subjetivo e de difícil medição). Tampouco se pretende afirmar que a ocorrência simultânea de todos esses elementos é condição necessária (e/ou suficiente) para que uma política tenha credibilidade.

${ }^{10}$ Por outro lado, em determinadas circunstâncias, a melhor solução pode ser eliminar qualquer flexibilidade e prender-se a uma regra inalterável. Um exemplo disso é o Plano Cavallo, implementado
} 
Uma segunda questão, relacionada à anterior, diz respeito à factibilidade dos objetivos traçados. Também aqui se aplicam as observações quanto à adoção de teorias distintas, mas há um complicador adicional, no que se refere às várias "etapas" a serem percorridas entre o anúncio (e implementação) de uma política e a efetivação dos resultados desejados (são os "long and variable lags" a que se refere Fricdman). De qualquer modo, a ideia é que não se pode acreditar em uma política que anuncia objetivos percebidos como inatingíveis.

Outro elemento a ser mencionado é a possibilidade de divergências internas na formulação da política monetária, tendo em vista o reconhecimento da multiplicidade de um governo "real". Nesse sentido, maior credibilidade deveria ser atribuída a uma política internamente consensual e que não fosse contraditória com outras metas e objetivos do governo.

Por fim, a consistência da política monetária também parece depender de sua coerência com outras políticas macroeconômicas (fiscal e cambial, especialmente). Tal coerência diz respeito tanto à compatibilidade entre os objetivos das diversas políticas como às interrelações que se estabelecem entre elas. Usando um exemplo bastante tradicional: em um país com grande mobilidade de capital e câmbio fixo, qualquer anúncio de política monetária ativa não deveria ter credibilidade, pois não se poderia garantir a priori determinada trajetória para a evolução do estoque monetário. Pode-se concluir, nesse caso, que as formas de elaboração da política fiscal e os regimes cambiais vigentes são elementos importantes para definir a consistência - e, consequentemente, a credibilidade - da política monetária. ${ }^{11}$

Por outro lado, cabe ainda discutir algumas questões relacionadas à capacidade de implementação da política monetária. Segundo Minsky (1986, p. 287), tratase de um dos principais problemas na "arte" da política monetária: "it is easy to list objectives, but much more difficult to deliver — to establish institutions and to start processes that will achieve these objectives".

A possibilidade de executar, de levar a cabo determinada política também parece influenciar a credibilidade a ela atribuída. Nesse caso, deve-se considerar obstáculos de natureza "técnica" e política.

A restrição "técnica" diz respeito ao grau de controle sobre as variáveis que se pretende influenciar e aos instrumentos de que os gestores podem fazer uso na condução e sustentação de determinada política. Ou seja, dever-se-ia atribuir maior

na Argentina, que condicionou a política monetária à entrada de divisas e fixou — por lei — a paridade peso-dólar, buscando resgatar a confiança na moeda local, após uma crise hiperinflacionária.

${ }^{11}$ Cabe, aqui, breve referência às propostas de "independência” do Banco Central. Num sentido estrito, $\mathrm{BC}$ independente seria aquele capaz de implementar uma política monetária não subordinada aos interesses do governo. No limite, a política monetária poderia, inclusive, seguir direção contrária à pretendida pelo governo na elaboração de outras políticas, como a fiscal. Segue-se, então, uma questão: a "independência" do BC levaria a um aumento da credibilidade da política monetária, mesmo podendo reduzir a coerência entre as diversas políticas macroeconômicas? Segundo a perspectiva adotada neste trabalho, a resposta não deve ser necessariamente positiva. 
credibilidade a certa política quando se percebe que o governo dispõe de mecanismos (técnicos) para executá-la e de "fôlego" para sustentá-la.

A segunda restrição se refere ao fato de uma ação de política monetária ser politicamente factível ou não. Importam aqui elementos ligados à capacidade política de implementação e resistência a pressões contrárias, representatividade e habilidade governamental etc. Segundo Laidler (1990, p. 74), "the most fruitful path in investigating [credibility] (...) lie in an analysis of the way in which private — and public-sector agents interact through political processes".

Em última instância, as restrições técnicas e políticas parecem desempenhar um papel mais relevante que aquele a elas atribuído pela visão convencional. A chamada restrição "estratégica", por sua vez, sobre a qual repousa toda a discussão ortodoxa sobre credibilidade, deixa de fazer sentido quando se abandona a proposição de que a política monetária só seria eficaz se inesperada. Prender-se estritamente a tal perspectiva significa ignorar aspectos essenciais no processo de formulação e implementação da política monetária.

Cabe ainda destacar que a consideração de restrições técnicas e políticas implica a necessidade de incorporar a influência de variáveis institucionais na questão da credibilidade. Ou seja, não se pode pensar tais problemas sem considerar o arcabouço institucional (banco central, sistema bancário e instituições políticas, por exemplo) no qual a política monetária é elaborada. Pois é certo que as possibilidades de atuação dos policy makers, as restrições enfrentadas, os instrumentos disponíveis e os canais de transmissão representados pelo sistema financeiro são institucionalmente determinados e condicionam a formulação e os resultados da política monetária. Ao contrário da visão tradicional, a existência de um banco central independente com regras fixas de emissão não parece ser condição necessária e suficiente para garantir a credibilidade da política monetária.

\section{CONSIDERAÇÕES FINAIS}

Este trabalho procurou apresentar duas óticas distintas para encarar a questão da credibilidade, que é reconhecida como um elemento que influencia os resultados da política monetária.

A primeira, que é hegemônica entre economistas acadêmicos e alcança algumas vezes a própria conformação dos bancos centrais (como no caso da Nova Zelândia, por exemplo), tem como fundamento a visão de que o sistema econômico é eminentemente estável e que políticas ativas são, além de desnecessárias, nocivas. Ademais, sugere que a política monetária só seria eficaz se inesperada e que, portanto, policy makers teriam estímulo a "trapacear", para promover elevações (ainda que transitórias) no nível de produto. A credibilidade, nesse caso, se relaciona à expectativa de que a política monetária não seja alterada, e pode ser obtida através de mecanismos que impossibilitem atuação discricionária por parte das autoridades monetárias ("mãos atadas”).

Entretanto, a não-aceitação das hipóteses que sustentam a teoria novo-clássi- 
ca - em particular, a suposta existência de uma taxa natural de desemprego, única e estável - invalida as proposições sobre credibilidade resumidas acima. A consideração de um sistema econômico que admite equilíbrios múltiplos leva a outros resultados quanto à operação da política monetária e, logo, à necessidade de se adotar uma perspectiva distinta para o problema da credibilidade.

Nesse sentido, o presente artigo buscou apresentar — a partir dos trabalhos de Keynes e dos chamados pós-keynesianos - uma visão alternativa sobre o tema. Em um sistema econômico sujeito a incerteza, em que os níveis de produção e emprego não convergem para um ponto pré-determinado, e em que a intervenção das autoridades monetárias se faz algumas vezes necessária, a credibilidade não dependeria da existência de regras fixas de emissão de moeda. Ao contrário, seria desprovido de credibilidade um banco central que não pudesse atuar de forma discricionária quando preciso. Nesse caso, a credibilidade se relacionaria não à percepção de que a política monetária não possa ser alterada, mas sim de que ela seja apropriada a uma conjuntura específica e ao fato de o banco central poder operar adequadamente as intervenções que se fizerem necessárias.

Por outro lado, há alguns elementos, mencionados de forma bastante introdutória neste trabalho, que mereceriam tratamento mais detalhado em pesquisas futuras sobre credibilidade. Um deles seria a interferência de variáveis políticas na elaboração e implementação da política monetária. Importam aqui as relações entre o banco central, outras instâncias decisórias do governo e os agentes privados. Outro ponto a ser melhor discutido seria o papel de aspectos institucionais na questão da credibilidade. Nesse caso, trata-se de avaliar como a configuração da autoridade monetária, do sistema bancário e demais instituições financeiras, entre outros, condiciona a formulação e os resultados da política monetária.

Em última instância, percebe-se que o problema da credibilidade depende de uma série de elementos, alguns dos quais possuem certo grau de subjetividade, e que a estrita adesão à visão convencional implica a desconsideração de aspectos essenciais no processo de implementação da política monetária. Vale insistir uma vez mais: a existência de um banco central independente com regras fixas de emissão não parece ser condição necessária e suficiente para garantir a credibilidade da política monetária.

\section{REFERÊNCIAS BIBLIOGRÁFICAS}

BARRO, R. (1976). "Rational expectations and the role of monetary policy". Reimpresso em: LUCAS , R., SARGENT, T., eds . (1981). Rational Expectations and Econometric Practice. Minneapolis: University of Minnesota Press.

BARRO, R., GORDON, D. (1983). " Rules, discretion, and reputation in a model of monetary policy”. Reimpresso em: PERSSON, T., TABELLINI, G., eds. (1994). Monetary and Fiscal Policy - vol. 1: Credibility. Cambridge, Mass.: The MIT Press.

BLACKBURN, K., CHRISTENSEN, M. (1989). "Monetary policy and policy credibility: theories and evidence". Journal of Economic Literature, vol. XXVII, March 1989.

CARVALHO, F.C. (1992). Mr. Keynes and the Post-Keynesians. Cheltenham: Edward Elgar. 
CARVALHO, F.C. (1994). “Temas de política monetária keynesiana “. Ensaios FEE, 15(1), pp. 33-61.

CARVALHO, F.C. (1997). "Economic policies for monetary economics". Revista de Economia Política, vol. 17, no 4 (68), out-dez. 1997.

CROSS, R., ed. (1995). The Natural Rate of Unemployment: reflections on 25 years of the hypothesis. Cambridge: Cambridge University Press.

DAVIDSON, P. (1978a). Money and the Real World. London: Macmillan, 2nd ed.

DAVIDSON, P. (1984). “Reviving Keynes's revolution”. Journal of Post- Keynesian Economics, vol. VI, $\mathrm{n}^{\circ}$ 4, summer 1984.

DAVIDSON, P. (1994). Post Keynesian Macroeconomic Theory. Aldershot: Edward Elgar.

DE LONG, B., SUMMERS, L. (1988). "How does macroeconomic policy affect output". Brookings Papers on Economic Activity, $\mathrm{n}^{\circ} 2$.

FAZZARI, S., MINSKY, H. (1984). “Domestic monetary policy: if not monetarism, what?”. Journal of Economic Issues, vol. XVIII, n 1, March 1984.

FRIEDMAN, M. (1968). “The role of monetary policy”. American Economic Review, vol. LVIII, nº 1, March 1968.

HAHN, F. (1981). Money and Inflation. Cambridge, Mass: The MIT Press.

HAHN, F. (1984). Equilibrium and Macroeconomics. Cambridge, Mass.: MIT Press.

KEYNES, J. M. (1982). A Teoria Geral do Emprego, do Juro e da Moeda. São Paulo: Ed. Atlas.

KEYNES, J. M. (s.d.) The Collected Writings of John Maynard Keynes. London. (indicados no texto por CWJMK, seguido do $\mathrm{n}^{\circ}$ do volume).

KREGEL, J. (1980). "Markets and institutions as features of a capitalistic production system”. Journal if Post Keynesian Economics, vol. 3, no. 1, fall 1980.

KYDLAND, F., PRESCOTI, E. (1977). "Rules rather than discretion: the inconsistency of optimal plans". Journal of Political Economy, vol.85, n.3.

LAIDLER, D. (1990). Taking Money Seriously. Cambridge, Mass.: The MIT Press.

LUCAS, R. (1983). Studies in Business Cycle Theory. Cambridge, Mass.: The MIT Press, first paperback edition.

LUCAS, R., SARGENT, T., eds. (1981). Rational Expectations and Econometric Practice. Minneapolis: University of Minnesota Press.

MINSKY, H. (1986). Stabilizing an Unstable Economy. New Haven: Yale University Press. PERSSON, T., TABELlinI, G., eds. (1994). Monetary and Fiscal Policy, vol. 1: Credibility. Cambridge, Mass.: The MIT Press.

SCHELLING, T. (1982). "Establishing credibility: strategic considerations". American Economic Review, vol.72, no.2, May.

SICSÚ, J. (1997). "Reputação das autoridades monetárias e credibilidade das suas políticas: uma abordagem pós-keynesiana”. Estudos Econômicos, vol.27, n. 1 .

TAYLOR, J. (1982). "Establishing credibility: a rational expectations viewpoint". American Economic Review, vol.72, no.2, May.

TOBIN, J. (1980). Asset Accumulation and Economic Activity. Chicago: The University of Chicago Press. 